\title{
A sensitivity analysis of the design parameters for thermal comfort of thermally activated building system
}

\author{
D G LEO SAMUEL ${ }^{1, *}, \mathrm{~S}^{\mathrm{M}}$ SHIVA NAGENDRA ${ }^{2}$ and M P MAIYA ${ }^{3}$ \\ ${ }^{1}$ Mechanical Engineering Department, Motilal Nehru National Institute of Technology Allahabad, Prayagraj, \\ India \\ ${ }^{2}$ Department of Civil Engineering, Indian Institute of Technology Madras, Chennai, India \\ ${ }^{3}$ Department of Mechanical Engineering, Indian Institute of Technology Madras, Chennai, India \\ e-mail: dglsam@gmail.com
}

MS received 30 May 2018; revised 27 September 2018; accepted 11 October 2018; published online 1 February 2019

\begin{abstract}
Thermally activated building system (TABS) can be operated at relatively higher water temperature. Hence, it can be coupled with passive cooling systems. This paper investigates the influences of three design parameters on thermal comfort of TABS using COMSOL Multiphysics, a computational fluid dynamics (CFD) tool. For the same inlet velocity, an increase in the pipe inner diameter from 9 to $17 \mathrm{~mm}$ decreased the operative temperature (OT), a thermal comfort index, by $1.8^{\circ} \mathrm{C}$. An increase in the pipe thermal conductivity from 0.14 to $1.4 \mathrm{~W} / \mathrm{mK}$ reduced the average OT by $2.5^{\circ} \mathrm{C}$. However, a further increase in thermal conductivity had no significant influence. For cooling pipes embedded at a constant depth, an increase in the thickness of both roof and floor from 0.1 to $0.2 \mathrm{~m}$ delayed and reduced the maximum OT by 48 minutes and $0.3^{\circ} \mathrm{C}$, respectively.
\end{abstract}

Keywords. Passive cooling; thermally activated building system; alternative technology; parametric analysis; design parameters; thermal comfort.

\section{Introduction}

Since time immemorial, attempts have been made to utilize the thermal mass of buildings to improve the thermal comfort of indoor space. "Ondol" also known as "gudeul" is an under-floor heating system, which has been in use in Korea since $1000 \mathrm{BC}$ [1]. A thick masonry floor is heated from beneath by hot air from a wood furnace during the day. The room remains warm during the night due to the high thermal mass of the thick floor. The major advantages of this system are uniform thermal comfort in the indoor space, good air quality, reduced fire accidents and low maintenance. "Kand" used in China and "hypocaust" used widely in the Roman Empire also work on the same principle $[2,3]$. Since the end of the nineteenth century, a similar principle has been used for comfort cooling applications with necessary modifications. This modified system is called chilled slab or thermally activated building system (TABS). In TABS, pipes are embedded in the structure and cold water is circulated through them to remove heat from the structure and indoor space. For transferring heat, water is preferred over air due to low pumping and capital cost. This is because, for the same volume, liquid water can

*For correspondence transfer approximately 3400 times more heat than gaseous air due to the high density and specific heat capacity of water.

This study simulates a room with TABS using a computational fluid dynamics (CFD) tool. Sensitivity analyses of three design parameters on the indoor thermal comfort have been carried out. The parameters chosen for the study are the inner diameter and thermal conductivity of pipes, and thickness of slabs (roof and floor). The room is simulated for the semi-arid climatic conditions of New Delhi, India. The simulation results are post-processed to obtain thermal comfort indices. The results presented in this paper would aid design engineers in finalising these three design parameters of TABS.

\section{Literature review}

The performance of TABS has been studied extensively in recent years. TABS is energy-efficient and eco-friendly. It provides better thermal comfort at a relatively lower initial and operating cost. TABS is reported to reduce primary energy consumption by approximately 50\% in hot and dry climatic conditions [4]. It also reduces the peak energy demand by 60 to $70 \%$ [5]. It provides superior thermal comfort due to the noise-free operation, absence of draft, low vertical temperature gradient and direct treatment of 
radiant load [6]. A numerical study reported that the average predicted mean vote (PMV) decreased from 0.75 for the conventional variable air volume system to 0.56 for ventilation assisted TABS [7]. The flexibility to operate the system when the energy cost is low (non-peak hours) is an added advantage. TABS can reduce the required chiller capacity by $50 \%$ compared to the conventional cooling system [8], thus reducing the initial cost. Further, TABS can be easily switched from cooling to heating mode and vice-versa.

The major advantage of TABS is its ability to achieve indoor thermal comfort at relatively higher water temperature. TABS can achieve an indoor operative temperature (OT) just $2^{\circ} \mathrm{C}$ higher than the supply water temperature [9]. This permits the use of passive cooling systems such as a nocturnal radiator, geothermal cooler [10] and cooling tower [11]. In Zurich, Switzerland, TABS integrated with a cooling tower maintained the indoor air temperature in the range of 22 to $26^{\circ} \mathrm{C}$ [12]. In Beijing, Shanghai and Guangzhou, TABS coupled with a cooling tower reduced the heat flux from the building structures to the indoor space by 305, 61 and $61 \%$, respectively [13]. Thus, the direction of heat flow is reversed and Beijing being at the dry climatic zone, i.e., the system not only eliminated the solar heat gain but also removed a part of the internal load. TABS has a few limitations such as the inability to handle latent load and high time constant. It is prone to leakage and condensation issues if not installed correctly and maintained properly. Nevertheless, in most cases, the advantages of TABS outweigh its limitations.

The cooling performance of TABS depends on the design and operating parameters of the system. However, studies to quantify the influence of various parameters on the performance of TABS are limited. Jin et al [14] investigated the influence of pipe thermal conductivity and water flow rate on the temperature distribution of floor with TABS. Antonopoulos et al [15] found that the spacing between the pipes, depth at which the pipes are embedded, supply temperature of water, temperature of indoor air and internal load of the space had a significant influence on the cooling performance of TABS, whereas those of the diameter of pipes and water flow rate were insignificant. Xie et al [16] investigated the influence of pipe spacing and supply water temperature on the heat flux of walls embedded with cooling pipes. However, all these studies are 2-D and limited to simulation of only the structure in which the pipes are embedded and estimation of its temperature distribution and surface heat flux. These studies do not quantify the thermal comfort achieved in the indoor space. Though there are a few studies on thermal comfort in such buildings, a few assumptions in these studies reduce the accuracy. For example, Kolarik et al [4], Hauser et al [17] and Ma et al [18] have assumed uniform indoor temperature while studying the influence of the thermal mass of the building with TABS.
Thus, the CFD simulation presented in this paper to investigate the influence of design parameters on the indoor thermal comfort indices is unique.

\section{CFD simulation}

A numerical model of a building with TABS (figure 1) was developed using COMSOL Multiphysics, a computational fluid dynamics (CFD) tool. The model was validated using experimental data from a test room constructed for this study. The validated model was used to study the influences of the three design parameters on the indoor thermal comfort. This section briefs the essentials of the numerical work. Model description, governing equations, boundary conditions, model validation and parameters investigated are presented below.

\subsection{Model description}

A room with dimensions of $3.46 \mathrm{~m} \times 3.46 \mathrm{~m} \times 3.15 \mathrm{~m}$ (figure 1) was used for the analysis. The roof and floor were made of $0.15 \mathrm{~m}$ thick concrete slabs and the walls were made of $0.23 \mathrm{~m}$ thick brick masonry. Air at ambient temperature and an inlet velocity of $0.1 \mathrm{~m} / \mathrm{s}$ was supplied through a $3 \mathrm{~m} \times 0.1 \mathrm{~m}$ opening at the base of the south wall. An opening of $0.8 \mathrm{~m} \times 0.8 \mathrm{~m}$ located on the north wall was used to vent out the excess air. Pipes were embedded on both roof and floor in a serpentine layout with a pipe spacing of $0.2 \mathrm{~m}$. Cooling water was supplied to the pipes at the wet bulb temperature of the ambient air and a uniform inlet velocity of $0.4 \mathrm{~m} / \mathrm{s}$. The room was modelled with a uniformly distributed internal cooling load of $15.6 \mathrm{~W} / \mathrm{m}^{3}$.

\subsection{Assumptions}

Following are the assumptions made in this study.

1. The Grashof number was of the order of $10^{9}$ (transition regime). The results of the simulation, with and without turbulence component, were compared and no significant variation was observed. Hence, the turbulence component was neglected in favour of computation time.

2. Due to a very high length to diameter ratio, the water flow in the embedded tube was assumed to be fully developed and axisymmetric. Thus, the flow is simplified as one-dimensional.

3. The heat transfer coefficient on the external surfaces of the building was assumed constant $\left(30 \mathrm{~W} / \mathrm{m}^{2} \mathrm{~K}\right)$. It was calculated based on the average wind speed that is experienced at the site.

4. The floor-ground surface was assumed to be adiabatic. 


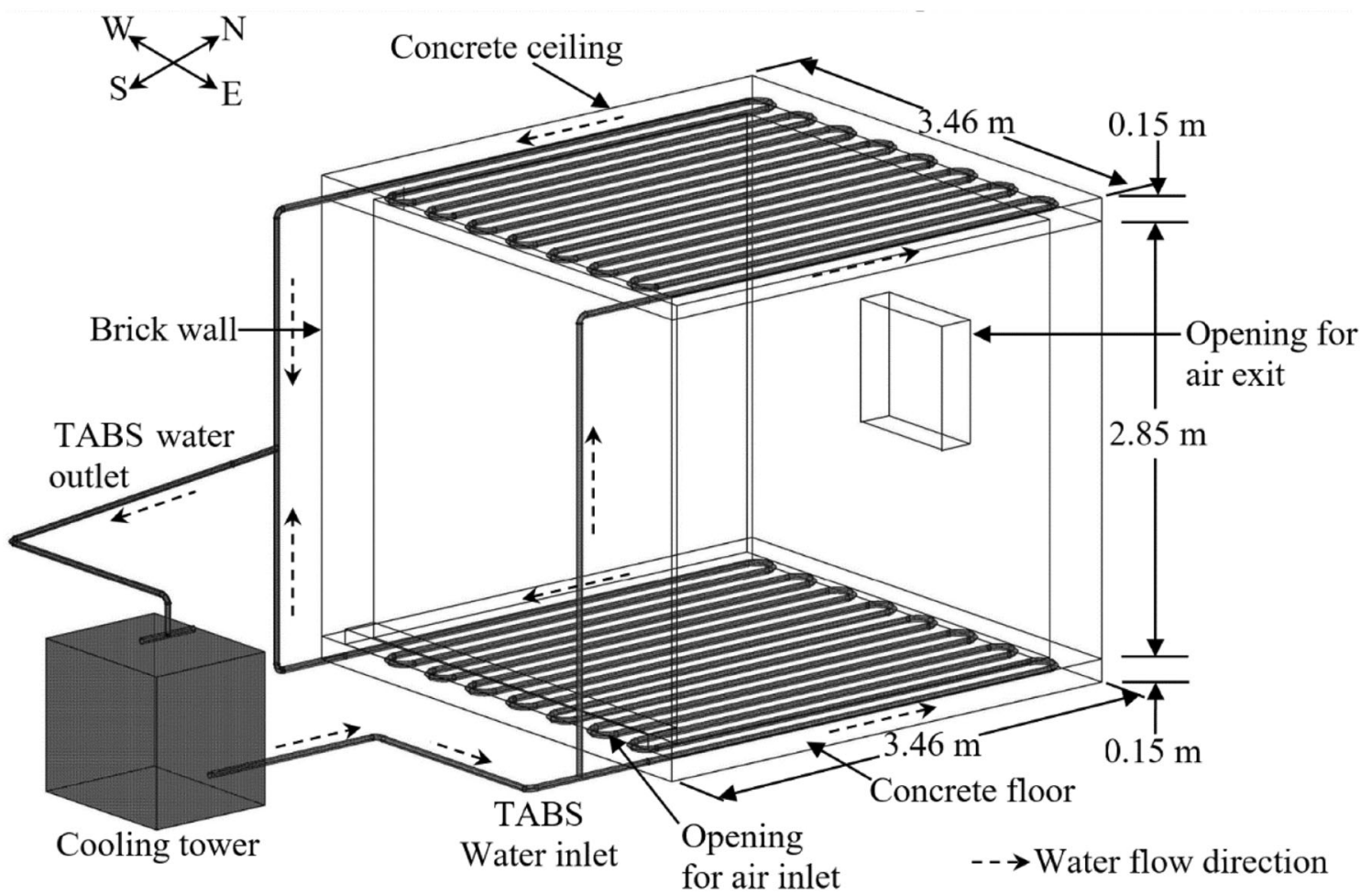

Figure 1. Schematic of a cooling tower based TABS [19].

\subsection{Governing equations}

The complete model could be classified into three domains, namely, indoor air, solid structures and water inside the cooling pipes. Equations (1)-(3) were the generalised governing equations used for the simulation.

$$
\begin{aligned}
& \frac{\partial \rho}{\partial \tau}+\nabla \cdot(\rho u)=0 \\
\rho\left[\frac{\partial u}{\partial \tau}+u \cdot \nabla u\right]= & -\nabla \mathrm{p} \\
& +\nabla \cdot\left(\mu\left(\nabla \mathbf{u}+(\nabla \mathrm{u})^{\mathrm{T}}\right)-\frac{2}{3} \mu(\nabla \cdot \mathrm{u}) \mathrm{I}\right) \\
& +\mathrm{f}
\end{aligned}
$$

$$
\rho C_{p}\left(\frac{\partial T}{\partial \tau}+u . \nabla T\right)=\nabla \cdot(k \nabla T)+Q
$$

The equations were simplified for the solid and water domains. For the former, as there was no movement, the velocity terms were made zero. For the latter, as the length to diameter ratio was very high, the governing equations were simplified to one-dimension along the centre-line of the pipe considering the flow as fully developed [20, 21]. Equations (4)-(6) were the governing equations for the water domain.

$$
\begin{gathered}
\frac{\partial A \rho}{\partial t}+\nabla \cdot(A \rho \bar{u})=0 \\
\rho \frac{\partial u}{\partial t}=-\nabla p-f_{D} \frac{\rho}{2 d_{h}} \bar{u}|\bar{u}|+f \\
\rho A C_{p} \frac{\partial T}{\partial t}+\rho A C_{p} \bar{u} . \nabla \mathrm{T}=\nabla \cdot A \mathrm{k} \nabla \mathrm{T}+\mathrm{f}_{\mathrm{D}} \frac{\rho A}{2 \mathrm{~d}_{\mathrm{h}}}|\overline{\mathrm{u}}|^{3}+\mathrm{Q}_{\text {wall }}
\end{gathered}
$$

In the present study, Churchill friction model was used to calculate the friction factor. The surface roughness of the pipe was assumed to be $0.0015 \mathrm{~mm}$. For turbulent flow, the Nusselt number used for calculating heat transfer between the cooling water and the pipe inner surface was calculated using Eq. (7) [22]. For laminar flow, the Nusselt number is taken as 3.66.

$$
\mathrm{Nu}=\frac{\left(\mathrm{f}_{\mathrm{D}} / 8\right)(\mathrm{Re}-1000) \operatorname{Pr}}{1+12.7 \sqrt{\left(\mathrm{f}_{\mathrm{D}} / 8\right)}\left(\operatorname{Pr}^{0.667}-1\right)}
$$

\subsection{Material properties}

The properties of the materials are one of the important inputs for CFD simulation. Table 1 presents the salient properties of air, water, brick and concrete. A few of the 
Table 1. Material properties.

\begin{tabular}{lcccc}
\hline Sl. no. & Parameter (unit) & Moist air* & Water* & Brick \\
\hline 1 & Density $\left(\mathrm{kg} / \mathrm{m}^{3}\right)$ & $\rho_{\mathrm{ma}}=\mathrm{f}\left(\mathrm{p}_{\mathrm{a}}, \mathrm{T}_{\mathrm{a}}, \mathrm{x}_{\mathrm{a}}\right)$ & 1000 & 2000 \\
2 & Dynamic viscosity $(\mathrm{kg} / \mathrm{ms})$ & $\mu_{\mathrm{ma}}=\mathrm{f}\left(\mathrm{T}_{\mathrm{a}}\right)$ & $\mu_{\mathrm{w}}=\mathrm{f}\left(\mathrm{T}_{\mathrm{w}}\right)$ & 2300 \\
3 & Specific heat $(\mathrm{J} / \mathrm{kgK})$ & 1005 & 4178 & 0 \\
4 & Thermal conductivity $(\mathrm{W} / \mathrm{mK})$ & $\mathrm{k}_{\mathrm{ma}}=\mathrm{f}\left(\mathrm{T}_{\mathrm{a}}, \omega\right)$ & $\mathrm{k}_{\mathrm{w}}=\mathrm{f}\left(\mathrm{T}_{\mathrm{w}}\right)$ & 1000 \\
\hline
\end{tabular}

$* \mathrm{f}()$ indicates that the parameter is a function of variables mentioned within the brackets.

properties such as density and viscosity were specified as functions of temperature and pressure ("Appendix-A").

\subsection{Boundary conditions}

The climatic conditions of New Delhi, India, specified the boundary conditions of the model. The weather data were obtained from an online meteorological database [23]. The boundary conditions on the external surface of walls and roof were specified with sol-air temperature and combined heat transfer coefficient $\left(30 \mathrm{~W} / \mathrm{m}^{2} \mathrm{~K}\right)$. The sol-air temperature was calculated from the ambient air temperature, solar intensity, surface absorptivity of solar radiation and combined heat transfer coefficient. The bottom surface of the floor was assumed to be adiabatic. Water was assumed to be supplied by a cooling tower at wet bulb temperature $\left(\mathrm{t}_{\mathrm{wb}}\right)$, which was calculated using Eq. (8) [24].

$$
\begin{aligned}
t_{w b}= & \left(t_{a}\right) \tan ^{-1}\left[0.151977(R H+8.313659)^{0.5}\right] \\
& +\tan ^{-1}\left(t_{a}+R H\right)-\tan ^{-1}(R H-1.676331) \\
& +0.00391838(R H)^{0.75} \times \tan ^{-1}(0.023101 R H) \\
& -4.686035
\end{aligned}
$$

\subsection{Solver settings}

The study variables changed with time and never reached a steady state. This was due to time-varying boundary conditions and a high thermal mass of the building. Hence, the study was set to be time-dependent. A linear multistep method named backward differential formula (BDF) was used for time stepping. In BDF method, the time step is varied based on convergence, i.e., shorter and longer timesteps are used when the convergence is poor and good, respectively. The generalised form of the BDF to solve $\mathrm{y}^{\prime}=\mathrm{f}(\mathrm{t}, \mathrm{y})$ is given by,

$$
\sum_{k=0}^{s} a_{k} y_{n+k}=h b f\left(t_{n+s}, y_{n+s}\right)
$$

The BDF formed a large sparse system of linear algebraic equations, which were solved by multifrontal massive parallel sparse direct solver (MUMPS) and parallel direct solver (PARADISO). Frontal solvers constructed a matrix by assembling element matrices. The matrix operations were carried out in the element matrices. The subset of the element matrix where the operation was executed is called front. Multifrontal solvers are advanced frontal solvers that can simultaneously handle many independent fronts. PARDISO combined left- and right-looking level-3 basic linear algebra subprograms (BLAS) supernode technique. Message passing interface (MPI) was used for parallel computation.

\subsection{Mesh independence and model validation}

Unstructured tetrahedral mesh was used (figure 2(a)). The size of the meshes differed with locations based on the physics (finer meshes were used in the boundary layers). The mesh independence test (figure 2(b)) was done to confirm that the mesh used had the required fineness to provide accurate results within low computation capacities. The number of mesh elements in this study was 332,224.

Validation is essential for CFD modelling. In this study, the model was validated with the experimental data obtained from the test facility, i.e., a $3.5 \mathrm{~m} \times 3.5 \mathrm{~m} \times 3.15 \mathrm{~m}$ (H) room supported by TABS. The test facility for this study was set-up on the premises of Indian Institute of Technology Madras, located in Chennai, India. The roof and floor of the room were constructed with $0.15 \mathrm{~m}$ thick concrete. The walls were constructed with cement brick with a thickness of $0.28 \mathrm{~m}$. Cross-linked polyethylene (PEX) pipes were embedded in both roof and floor in a serpentine arrangement, with a pipe spacing of $0.2 \mathrm{~m}$. The thickness and inner diameter of the pipes were 2 and $16 \mathrm{~mm}$, respectively. In the roof and floor, the pipes were placed at a distance of 50 and $60 \mathrm{~mm}$ from their respective inner surfaces. The north and south walls of the room had a glazed window each. Individual window measured $1.5 \mathrm{~m} \times 1.21 \mathrm{~m}$. The partially glazed door on the west wall measured $1.2 \mathrm{~m} \times 2.12 \mathrm{~m}$. The indoor comfort parameters such as the temperature of indoor air and inner surfaces, and humidity and velocity of indoor air, outdoor conditions and water temperature were monitored continuously. The uncertainty of measured data was within $\pm 2.4 \%$.

The thermal condition of the room was transient and exhibited spacial variation due to high thermal mass and ever-changing boundary conditions. It proved to be a challenge to specify the initial conditions for the simulation. To overcome this challenge, the simulations were 

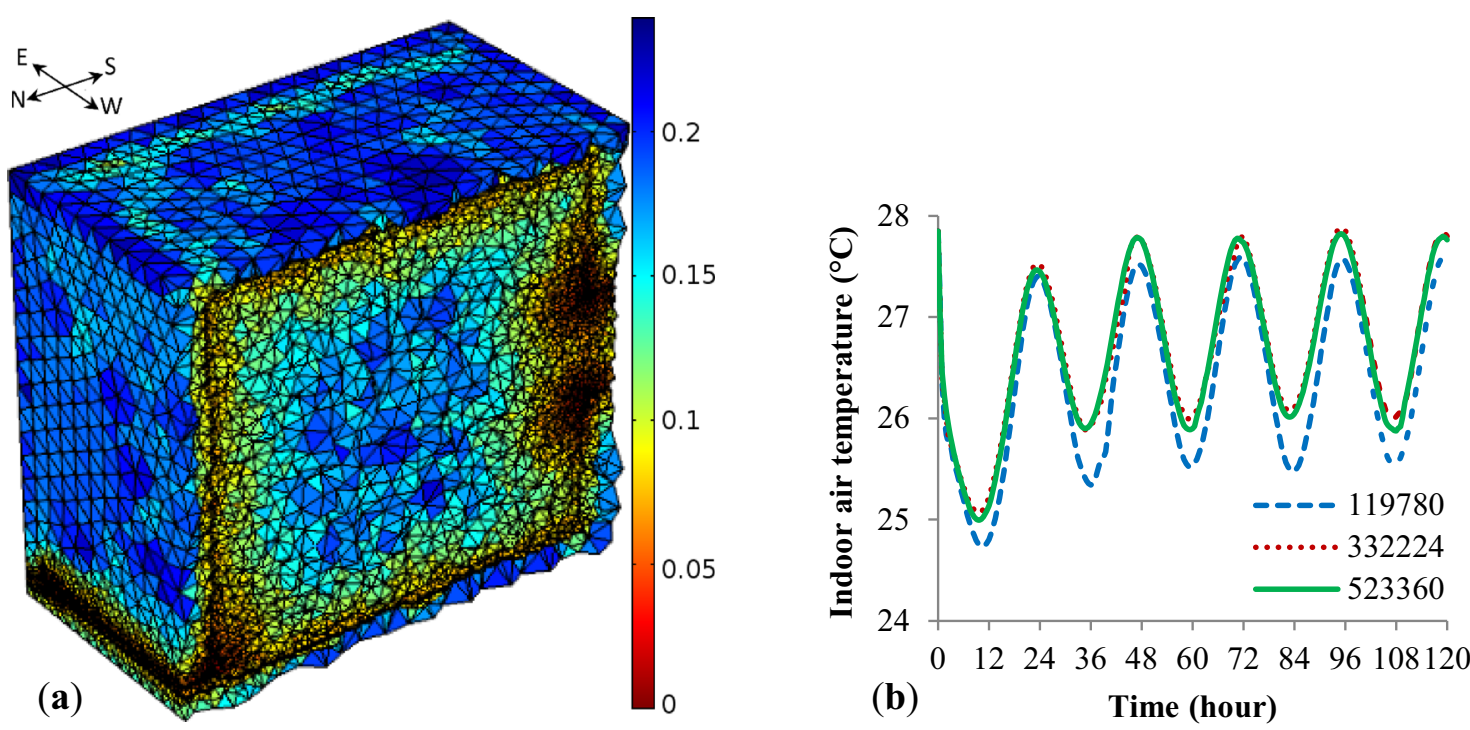

Figure 2. Meshing (a) mesh size on the cross-section plane facing west direction and located at the center of the room, (b) mesh independence analysis.

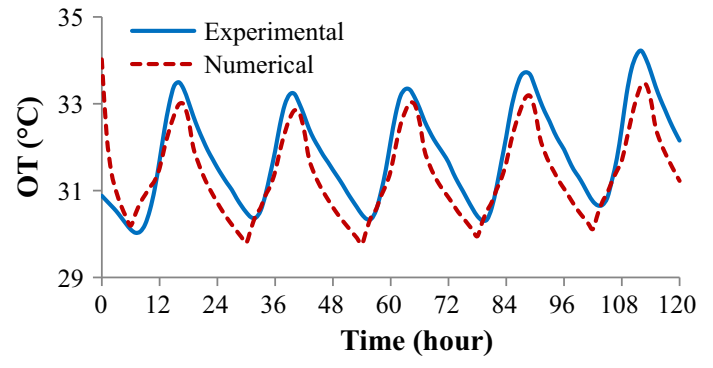

Figure 3. Model validation [19].

started with a uniform initial temperature approximately equal to the average ambient temperature. The simulation was continued for a study duration of multiple days. It was observed that the numerical results were independent of the above assumed initial temperature after four days. In other words, for various initial conditions, the differences between numerical results were negligible starting from the fifth day. Hence, the fifth-day results alone have been considered in this study. On the fifth day, the numerical results were found to agree well with the experimental data. Figure 3 presents the comparison of OT between experimental and numerical results. The numerical simulation result of other comfort parameters such as PMV and PPD also matched well with the experimental data.

\subsection{Parameters investigated}

Table 2 lists the parameters investigated along with their ranges, increments and default values. To study the influence of one parameter, the particular parameter was varied while keeping the other two parameters at their default values. Pipe diameter and slab thickness were varied in arithmetic progression. Preliminary studies indicated that the indoor thermal comfort was influenced greatly by pipe thermal conductivity at lower values. Hence, to capture the influence clearly, more points were needed at lower thermal conductivity. Therefore, pipe thermal conductivity was varied in geometric progression with a multiplication factor of 3.2 .

Further details on model validation, mesh independence analysis, numerical techniques used for simulation and comfort indices used for post-processing of results have been presented in an earlier paper by the same authors [19].

\section{Results and discussion}

The performance of a TABS was analysed in terms of temperature of indoor air and room inner surfaces, and comfort indices, namely, OT [25], PMV [26] and predicted percentage of dissatisfied (PPD) [27]. The indoor air

Table 2. Parameters investigated.

\begin{tabular}{|c|c|c|c|c|}
\hline Sl. no. & Parameter (unit) & Range & Increment* & Default \\
\hline 1 & Pipe inner diameter $(\mathrm{mm})$ & $9-17$ & +2 & 13 \\
\hline 2 & Pipe thermal conductivity $(\mathrm{W} / \mathrm{mK})$ & $0.14-4.5$ & $\times 3.2$ & 0.45 \\
\hline 3 & Roof and floor thickness (m) & $0.1-0.2$ & +0.025 & 0.15 \\
\hline
\end{tabular}

$*+$ and $\times$ indicate arithmetic and geometric progression, respectively 
velocity in the occupied zone was within the comfort limits at all times for all the cases. It was not influenced significantly by the investigated parameters. Hence, this is not discussed in detail. The air velocity was accounted while calculating PMV.

\subsection{Pipe inner diameter}

The pipe inner diameter was varied from 9 to $17 \mathrm{~mm}$ in steps of $2 \mathrm{~mm}$. Two cases were studied, one with a constant flow rate of $3.2 \mathrm{l} / \mathrm{min}$ and the other with a constant inlet velocity of $0.4 \mathrm{~m} / \mathrm{s}$.

4.1a Constant flow rate: An increase in pipe diameter would increase the heat transfer area between the water and the pipe and between the pipe and the building structure in which the pipe is embedded. This would enhance the rate of heat removal from the building structures and in turn the indoor air. Alternatively, it can be said that an increase in pipe inner diameter from 9 to $17 \mathrm{~mm}$ at a constant flow rate, would reduce the velocity of water by $72 \%$. This would allow the water to stay in the pipes longer by $257 \%$. The extra time spent by the water would allow more heat to be removed by it. However, for a constant flow rate, a higher heat removal would increase the water temperature. Thus, the temperature potential that drives the heat transfer would reduce rapidly along the direction of flow in the higher diameter pipes. This, in turn, would counteract the increase in heat removed by the cooling water. In addition, the increase in pipe diameter would reduce the velocity of water and in turn the heat transfer coefficient. Therefore, an increase in pipe diameter at a constant flow rate would only marginally increase the cooling performance of TABS.

The increase in pipe inner diameter from 9 to $17 \mathrm{~mm}$ increased the rate of heat removal by the water circulating through the roof and floor by 225 and $34 \mathrm{~W}$, respectively. This decreased the average temperature of the floor and roof inner surfaces by 0.7 and $1.1^{\circ} \mathrm{C}$ respectively (figure 4(a)). This, in turn, decreased the average temperature of the indoor air and walls by convection and radiation. For the pipe diameter of $17 \mathrm{~mm}$, the average temperatures of both indoor air and walls were $0.5^{\circ} \mathrm{C}$ lower than that of the pipe diameter of $9 \mathrm{~mm}$. An increase in pipe diameter would reduce the thermal comfort indices (favourable) due to the decrease in temperature of the indoor air and inner surfaces of the room. When the pipe diameter was increased from 9 to $17 \mathrm{~mm}$, the average OT, PMV and PPD were reduced by $0.5^{\circ} \mathrm{C}, 0.16$ and $4.4 \%$, respectively.

Figure 4(b) represents the diurnal variation of OT. During late evening and early morning hours, the ambient temperature dropped due to the absence of solar radiation. This resulted in a drop of OT during morning hours. The drop in OT continued till 8:30 due to the thermal inertia of the building. After this, the OT increased, due to increase in ambient temperature and heating of the building by solar radiation, and reached its maxima at 20:00. The pipe diameter was found to have no significant influence on the time at which the extrema of the comfort indices were reached. It also did not alter the diurnal fluctuation of comfort parameters. The diurnal fluctuation of the OT was the same at $5.4^{\circ} \mathrm{C}$ for the various pipe diameters.

4.1b Constant inlet velocity: In the case of constant inlet velocity, an increase in the pipe diameter would result in a quadratic increase of water flow rate. Thus, for a higher diameter pipe, a large quantity of water at a low temperature is available for heat dissipation. This would slow down the temperature increase along the serpentine loop (figure 5), in spite of a higher rate of heat removal. The average rate of heat removed by the cooling water in TABS of the roof and floor was 702 and $106 \mathrm{~W}$ higher for the $17 \mathrm{~mm}$ pipes compared to that of the $9 \mathrm{~mm}$ pipes. Nevertheless, the average temperature of the water at the exit of the TABS in roof and floor was 7.7 and $3.6^{\circ} \mathrm{C}$ lower for the $17 \mathrm{~mm}$ pipes than that of the $9 \mathrm{~mm}$ pipes. The higher rate
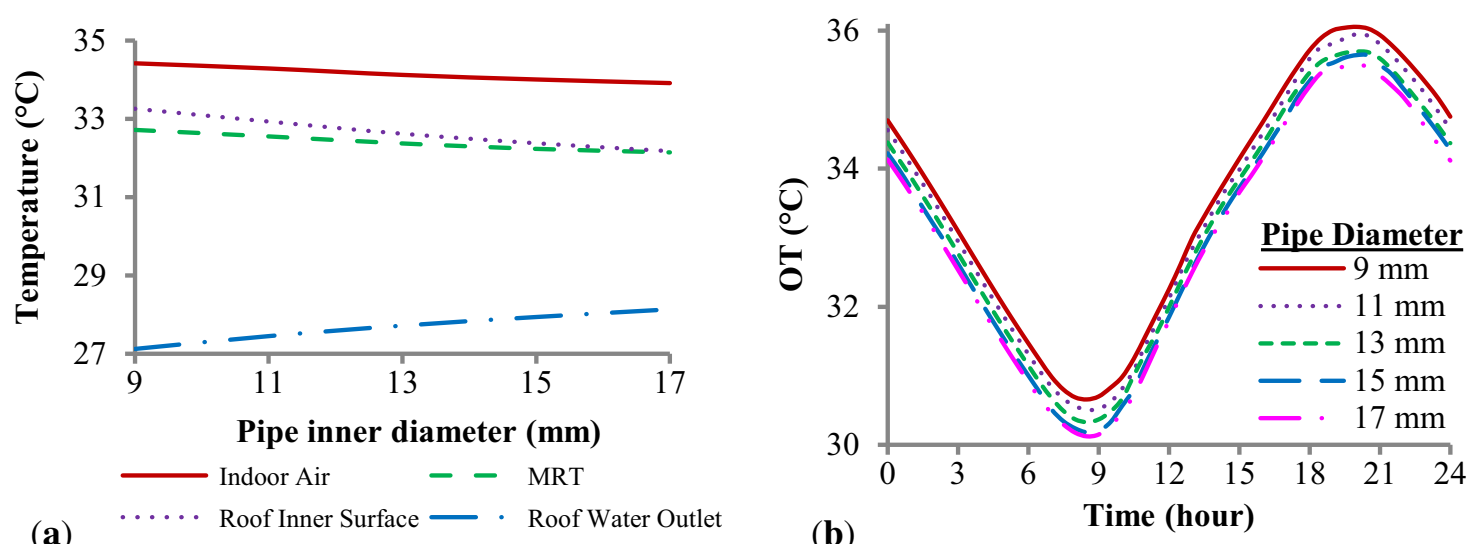

Figure 4. Influence of pipe diameter change at a constant flow rate on the (a) diurnal average temperatures (b) diurnal fluctuation of OT. 


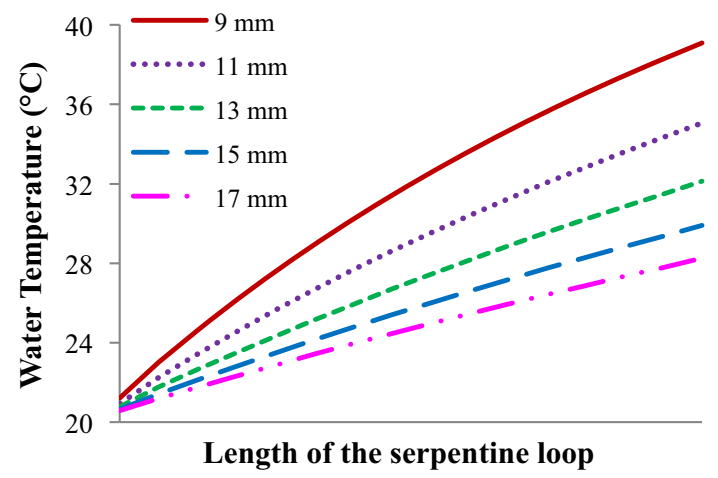

Figure 5. Water temperature along the length of the serpentine loop of pipe in the roof at 16:00 for the different pipe diameters.

of heat removal, for the higher diameter pipe, improved the cooling performance of TABS.

Cooling water in the pipes would not only remove heat from the indoor space but also reduce heat penetration from the outdoor to indoor space. Figure 6 compares the temperature distribution of the roof on a vertical plane perpendicular to the cooling pipes and located in the middle of the roof. The inner part of the roof was at a lower temperature (blue colour) and more uniform for the pipe diameter of $17 \mathrm{~mm}$. However, for the pipe diameter of $9 \mathrm{~mm}$, the spaces between the pipes were at a higher temperature (red colour). Thus, TABS with the higher diameter pipes was more effective in preventing external heat penetration. This decreased the average and diurnal fluctuation of the roof temperature by 3.7 and $2.9^{\circ} \mathrm{C}$, respectively, for $17 \mathrm{~mm}$ pipes compared to that of $9 \mathrm{~mm}$ pipes. A lower and uniform temperature of the roof inner surface, for the higher diameter pipes, would improve the indoor thermal comfort.

Figure 7 represents the impact of the change in pipe diameter on the diurnal averages. For TABS with $9 \mathrm{~mm}$ pipes, the average temperatures of the indoor air and of the walls were 35.2 and $35.6^{\circ} \mathrm{C}$, respectively. These reduced by 1.7 and $1.5^{\circ} \mathrm{C}$ respectively, for TABS with $17 \mathrm{~mm}$ pipes. These reductions were due to an increase in convective and

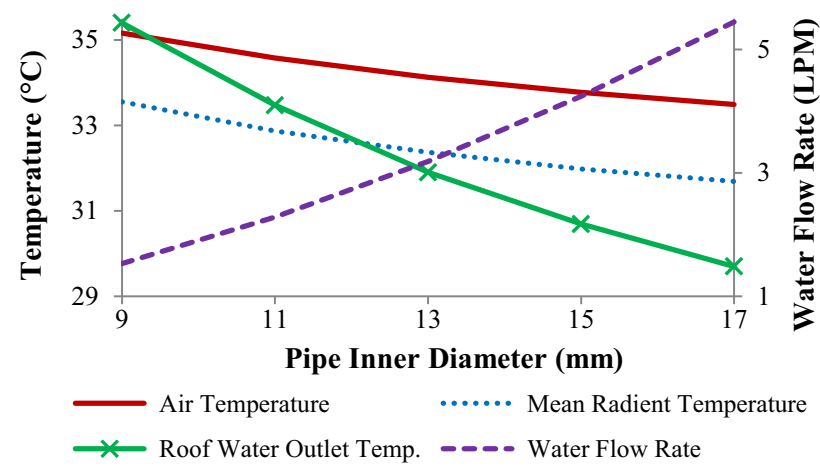

Figure 7. Influence of pipe inner diameter at constant water inlet velocity.

radiative heat removal by the colder roof and floor for higher diameter pipes. The MRT reduced by $1.9^{\circ} \mathrm{C}$ with an increase in pipe inner diameter from 9 to $17 \mathrm{~mm}$.

A decrease in temperature of the indoor air and MRT for an increase in pipe diameter would decrease the comfort indices. For TABS with $9 \mathrm{~mm}$ pipes, the diurnal average of OT, PMV and PPD were $34.3^{\circ} \mathrm{C}, 2.7$ and $91.1 \%$, respectively (figure 8 ). These reduced by $1.8^{\circ} \mathrm{C}, 0.5$ and $13.6 \%$, respectively, when the pipe diameter was increased to $17 \mathrm{~mm}$. The diurnal fluctuation of OT reduced by $0.2^{\circ} \mathrm{C}$ for an increase in pipe diameter from 9 to $17 \mathrm{~mm}$. Pipe diameter had no appreciable influence on the time at which the extrema of comfort indices were reached.

From the two cases investigated, it can be concluded that an increase in pipe diameter should be accompanied by an optimized increase in water flow rate for a significant improvement in the cooling performance of TABS.

\subsection{Pipe thermal conductivity}

Pipes of thermal conductivity 0.14 (chlorinated polyvinyl chloride-CPVC), 0.45 (cross-linked polyethylene-PEX), 1.4 (equal to concrete) and $4.5 \mathrm{~W} / \mathrm{mK}$ (higher than concrete) were compared to study the impact on the cooling performance of TABS. To understand the influence of pipe

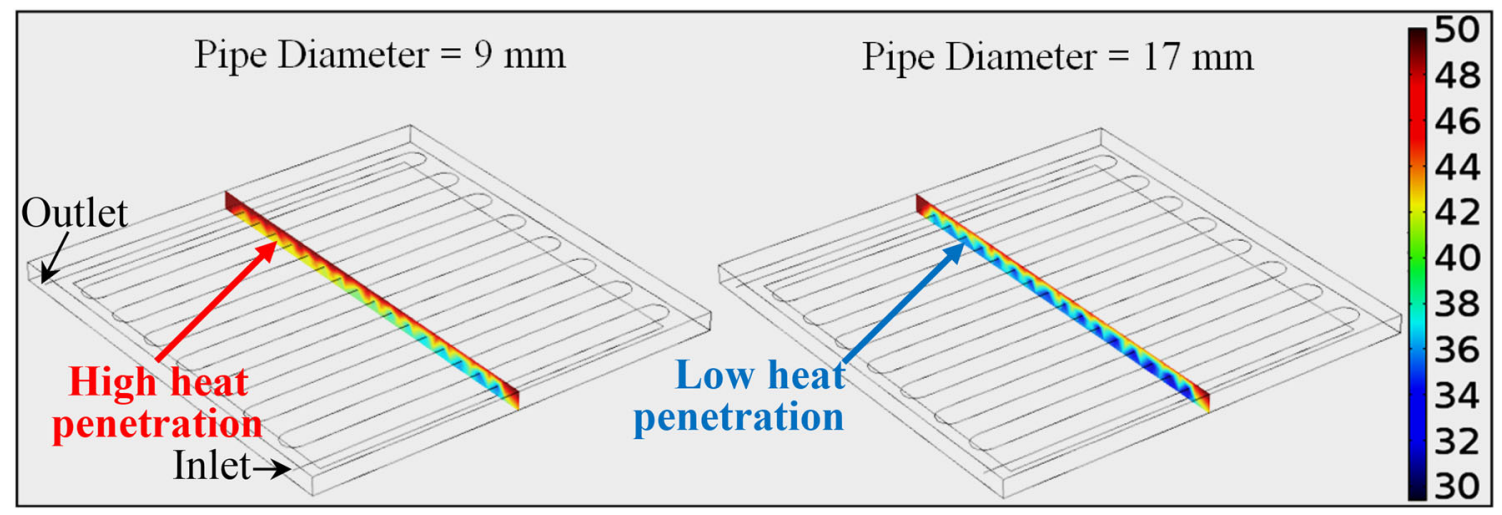

Figure 6. Temperature distribution $\left({ }^{\circ} \mathrm{C}\right)$ in a vertical plane at 16:00. 

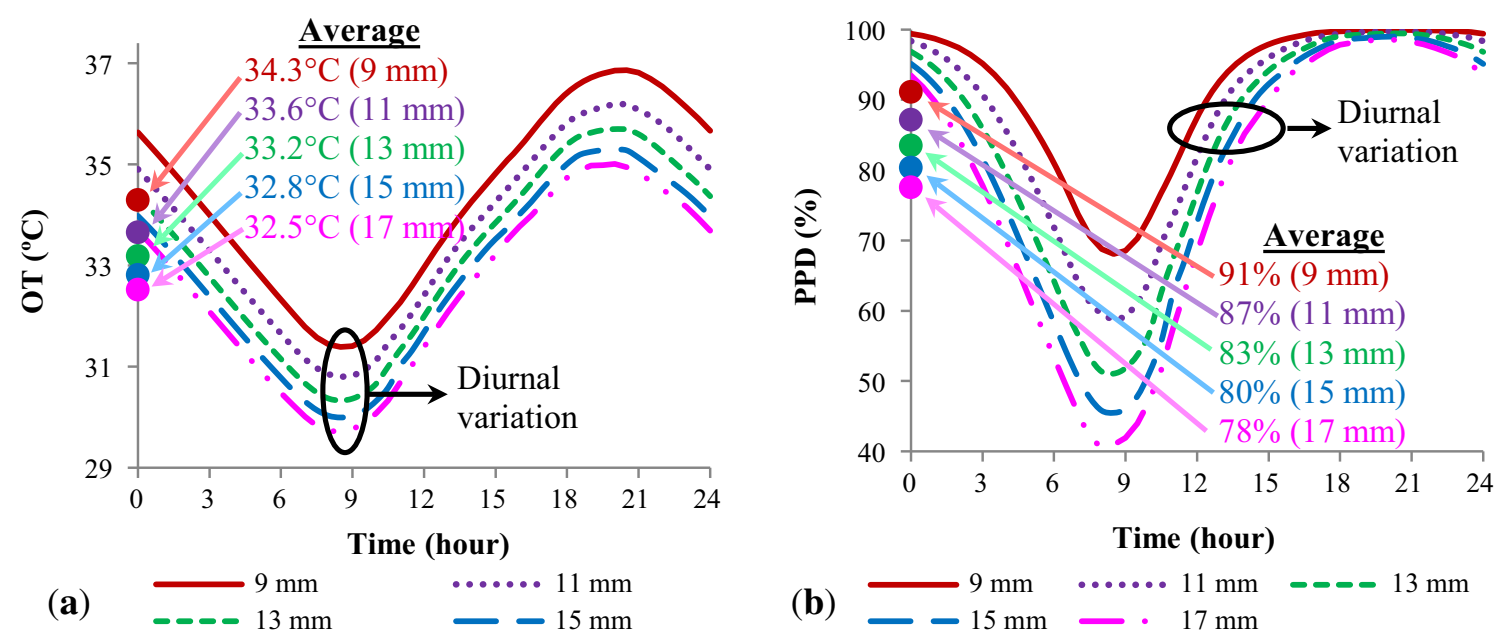

Figure 8. Diurnal variation and average of (a) OT and (b) PPD for different pipe inner diameters at constant inlet velocity.
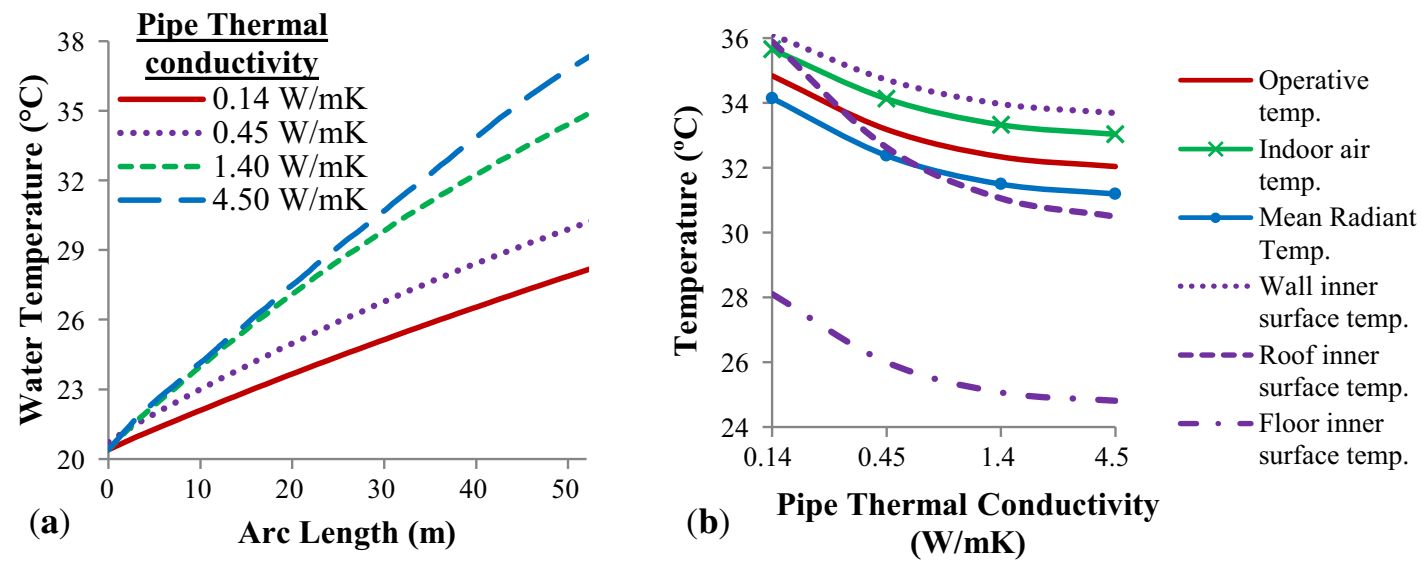

Figure 9. Influence of pipe thermal conductivity on (a) temperature of the water inside the pipes embedded in the roof at 15:00 and (b) diurnal average of indoor temperatures.

thermal conductivity in relation to the thermal conductivity of the structure, pipe materials with thermal conductivity equal to and greater than concrete were studied. PEX is widely used in TABS; hence, it was considered as the default pipe material in this study.

An increase in the thermal conductivity of the pipes would enhance heat transfer from the structure to the cooling water. This is evident from the rapid increase in the temperature of water flowing through the pipes of higher thermal conductivity (figure 9(a)). The increase in pipethermal conductivity from 4.5 to $0.14 \mathrm{~W} / \mathrm{mK}$ increased the average outlet temperatures of water in the roof and floor pipes by 4.8 and $0.8^{\circ} \mathrm{C}$, respectively. Thus, the increase in pipe thermal conductivity increased the heat removal rate of TABS in the roof and the floor by 1059 and $178 \mathrm{~W}$, respectively. This decreased the temperature of the inner surface of the roof and floor by 5.4 and $3.3^{\circ} \mathrm{C}$, respectively (figure $9(\mathrm{~b})$ ). These, in turn, decreased the indoor air and wall inner surfaces temperature by 2.6 and $2.4^{\circ} \mathrm{C}$, respectively through convective and radiative heat transfer. The comfort indices, namely, OT, PMV and PPD decreased (favourable) by $2.8^{\circ} \mathrm{C}, 0.8$ and $21 \%$, respectively for the increase in pipe thermal conductivity from 0.14 to $4.5 \mathrm{~W} / \mathrm{mK}$.

In the roof, a part of the cooling was wasted in cooling its external surface. No such wastage occurred in the floor as its underside is considered to be adiabatic. Hence, a low change in heat removal $(178 \mathrm{~W})$ is effective in reducing its inner surface temperature $\left(3.3^{\circ} \mathrm{C}\right)$ as compared to that of the roof ( $1059 \mathrm{~W}$ caused $5.4^{\circ} \mathrm{C}$ change). In addition, the convective heat transfer coefficient of the floor is low due to low indoor air movement in its vicinity. This is also responsible for the higher change in inner surface temperature of the floor for a low change in its rate of heat transfer.

Figure 10 depicts the diurnal variation and average of OT for TABS with pipes of different thermal conductivity. The thermal conductivity of pipes had marginal influence on the amplitude of diurnal fluctuation. It had no significant effect on the time at which the extrema of the OT 


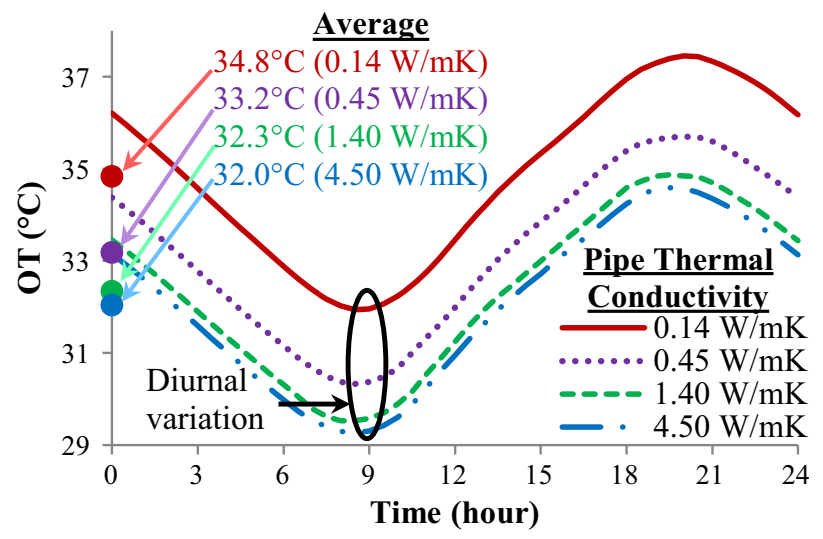

Figure 10. Influence of pipe thermal conductivity on diurnal variation and the average of OT

were reached. It had a significant influence on average OT only when it was lower than that of the thermal conductivity of the slab material. For example, the average OT was reduced by $2.5^{\circ} \mathrm{C}$ when the thermal conductivity was increased from 0.14 to $1.4 \mathrm{~W} / \mathrm{mK}$ (thermal conductivity of slab material). However, increasing the thermal conductivity further by $3.1 \mathrm{~W} / \mathrm{mK}$ reduced the average OT only by $0.3^{\circ} \mathrm{C}$. Thus, a decrease in thermal conductivity of pipe below that of the slab would result in a sharp fall in the cooling performance of TABS. Therefore, pipe material with a thermal conductivity equal to or greater than that of slab material would be preferable. Other factors such as corrosion resistance, flexibility, ease of joining and leak proof joints must also be considered while finalising the pipe material.

\subsection{Roof and floor thickness}

The thickness of roof and floor (referred as slabs in this section) were made equal and were varied from 0.1 to $0.2 \mathrm{~m}$ in steps of $0.025 \mathrm{~m}$. Two cases were studied. In
Case-1, the pipes were embedded at a depth of $0.05 \mathrm{~m}$ from the inner surface of the slabs and in Case-2, they were placed in the middle of the slabs.

4.3a Cooling pipes at a fixed depth from the inner surface: If the pipes were placed at a constant distance from the inner surface, the distance between the pipes and the outer surface would increase with an increase in thickness of the slab. This would increase the thermal resistance between the cooling water and the outer surface, which, in turn, would reduce the heat removed by the cooling water from the outer surface. Thus, for a slab with a higher thickness, the cooling water would be utilised more effectively in removing the heat from the inner surfaces. Hence, an increase in thickness of the slabs would increase the temperature of the roof outer surface and would decrease the temperature of its inner surface. For the slab thickness of $0.1 \mathrm{~m}$, the average temperatures of the roof's inner and outer surfaces were 25.8 and $38.8^{\circ} \mathrm{C}$, respectively. The former was reduced by $1.6^{\circ} \mathrm{C}$ (figure $11(\mathrm{a})$ ), whereas the latter was increased by $2.8^{\circ} \mathrm{C}$ when the thickness of the slabs was increased to $0.2 \mathrm{~m}$. An increase in thickness of the slabs would reduce the diurnal temperature fluctuation of the inner surface of the slabs. This is attributed to the increase in thermal mass. The diurnal temperature fluctuation of the roof inner surface was $9.5^{\circ} \mathrm{C}$ for the slab thickness of $0.1 \mathrm{~m}$. This reduced to $6.6^{\circ} \mathrm{C}$ when the thickness of the slabs was increased to $0.2 \mathrm{~m}$ (figure 11(a)).

The increase in thickness of the slabs had a similar influence on the temperature of the indoor air and the comfort indices. However, the magnitude of influence was relatively low. An increase in the thickness of the slabs from 0.1 to $0.2 \mathrm{~m}$ reduced the diurnal average of indoor air temperature and $\mathrm{OT}$ by 0.4 and $0.3^{\circ} \mathrm{C}$, respectively. It also reduced the diurnal fluctuation of these two parameters by 0.6 and $0.4^{\circ} \mathrm{C}$ (figure $11(\mathrm{~b})$ ), respectively. An increase in thickness of the slabs from 0.1 to $0.2 \mathrm{~m}$ delayed the maximum OT by 48 minutes, while the minimum was delayed by 50 minutes. It also delayed the extrema of other comfort
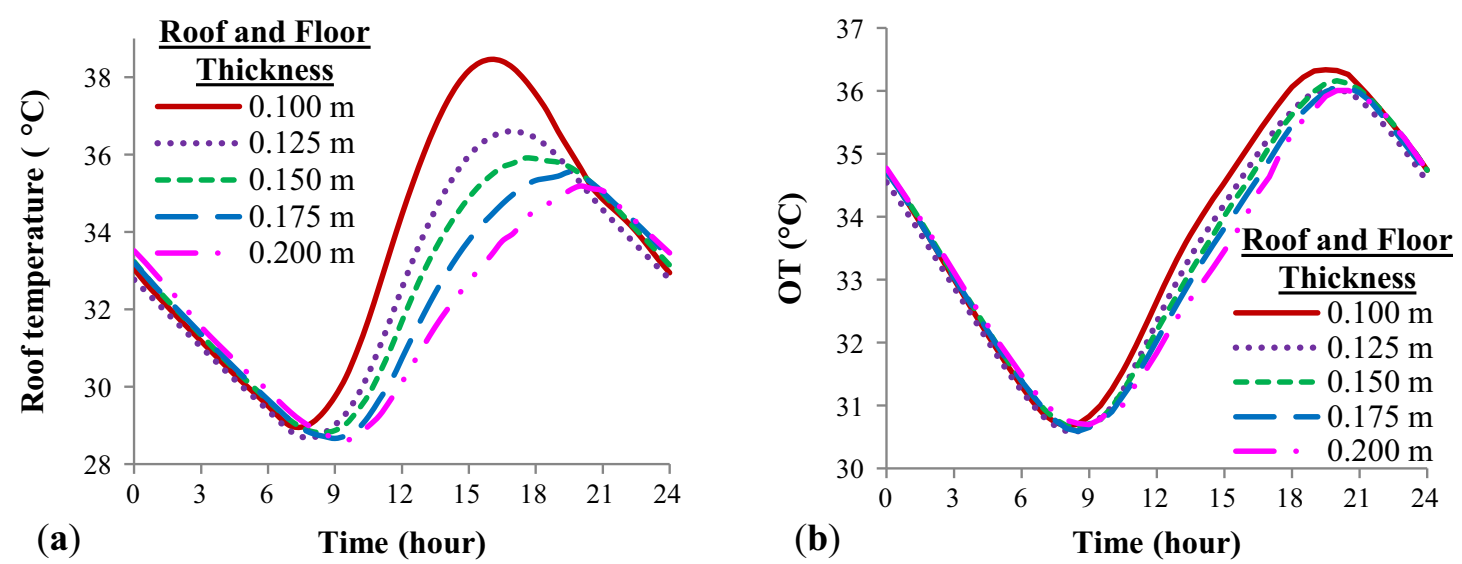

Figure 11. Influence of slab thickness on diurnal fluctuation of (a) temperature of roof inner surface and (b) OT for Case-1. 
Table 3. Influence of slab thickness on time lag for Case-1.

\begin{tabular}{|c|c|c|c|c|c|c|c|}
\hline \multirow[b]{2}{*}{ Sl. no. } & \multirow[b]{2}{*}{ Parameter } & \multicolumn{5}{|c|}{ Time at which maximum temperature is reached } & \multirow[b]{2}{*}{ Time lag between 0.1 and $0.2 \mathrm{~m}$} \\
\hline & & $0.1 \mathrm{~m}$ & $0.125 \mathrm{~m}$ & $0.15 \mathrm{~m}$ & $0.175 \mathrm{~m}$ & $0.2 \mathrm{~m}$ & \\
\hline 1 & Outer roof temperature & $13: 42$ & $13: 48$ & $13: 55$ & $14: 00$ & $14: 04$ & $0: 22$ \\
\hline 2 & Inner roof temperature & $16: 04$ & $16: 56$ & $17: 40$ & $19: 32$ & 20:01 & $3: 57$ \\
\hline 3 & Indoor air temperature & $18: 32$ & $18: 40$ & $19: 37$ & $19: 49$ & $19: 49$ & $1: 17$ \\
\hline 4 & MRT & 20:07 & $20: 10$ & $20: 23$ & $20: 28$ & $20: 28$ & $0: 21$ \\
\hline 5 & OT & $19: 28$ & $19: 49$ & 20:00 & $20: 14$ & $20: 16$ & $0: 48$ \\
\hline
\end{tabular}

parameters (table 3 ) due to the increase in thermal mass of the building.

4.3b Cooling pipes at the centre of the slabs: In Case-2, the pipes were placed at the centre of the slabs. Hence, an increase in slab thickness would move the pipes away from both interior and exterior surfaces. This would increase the thermal resistance between cooling water and the surfaces of the slabs. As a result, the cooling water would remove less heat from the slabs in which the cooling pipes were embedded. For the increase in slab thickness from 0.1 to $0.2 \mathrm{~m}$, the average heat removed by the cooling water circulating through the roof decreased by $215 \mathrm{~W}$. A major portion of this reduction was from the exterior surface of the roof, whereas the reduction in heat removed from the roof interior surface was $20.9 \mathrm{~W}$ only. The heat removed from the interior surface of the floor was $35.9 \mathrm{~W}$ lower for the slab thickness of $0.2 \mathrm{~m}$ compared to that of $0.1 \mathrm{~m}$. These increased the temperatures of the inner surfaces and the indoor air, and comfort indices (unfavourable) marginally. For an increase in slab thickness from 0.1 to $0.2 \mathrm{~m}$, the diurnal average of OT, PMV and PPD increased by $0.4^{\circ} \mathrm{C}, 0.14$ and $3.6 \%$, respectively. Similar to Case- 1 , an increase in the thickness of the slabs would reduce the fluctuation of comfort parameters and would delay the extrema of these parameters. An increase in slab thickness from 0.1 to $0.2 \mathrm{~m}$ reduced the diurnal temperature fluctuation of the roof inner surface by $2.1^{\circ} \mathrm{C}$ (figure 12), and the

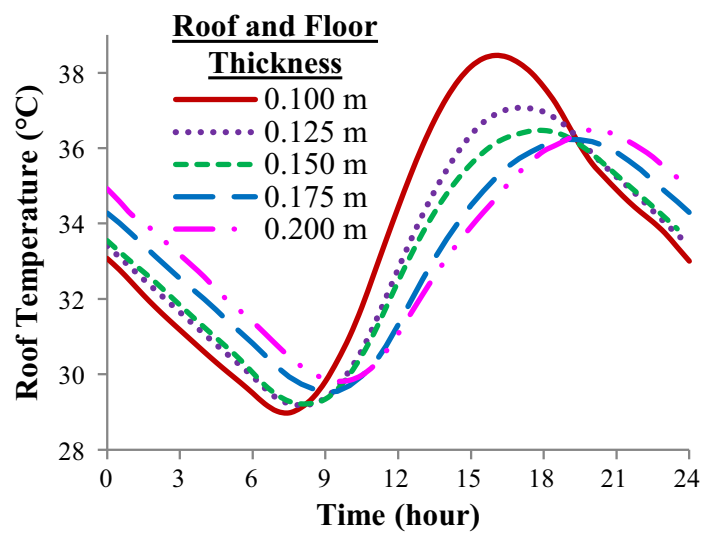

Figure 12. Influence of slab thickness on the inner surface temperature of the roof for Case-2. fluctuation of OT and PPD decreased by $0.3^{\circ} \mathrm{C}$ and $11 \%$ respectively. For the slab thickness of $0.1 \mathrm{~m}$, the temperature of roof inner surface reached its maximum at 16:04. This was delayed by four hours when the slab thickness was increased to 0.2 .

\subsection{Comparison between the best and worst combinations}

The best and worst combinations (table 4) of the design parameters, based purely on cooling performance, were compared to estimate the combined influence of the three design parameters. In this comparison, the inlet velocity of water was assumed to be constant. Hence, the water flow rates were 5.4 and $1.5 \mathrm{l} / \mathrm{min}$. for the best and worst cases, respectively. The best combination of the three design parameters reduced the OT, PMV and PPD by $4.7^{\circ} \mathrm{C}, 1.4$ and $36.7 \%$, respectively compared to the worst combination. However, this additional cooling can be obtained only with additional capital and operational cost.

The increase in pipe diameter at constant inlet velocity would increase both capital and operational cost due to the increase in water flow rate. Pump power consumption is directly proportional to the water flow rate and pressure drop. The water flow rate in the $17 \mathrm{~mm}$ pipe was 3.6 times higher than that of the $9 \mathrm{~mm}$ diameter pipe. The pressure drop of the pipes embedded in the roof and floor was $10.5 \mathrm{kPa}$ lower for the $17 \mathrm{~mm}$ diameter pipe. Hence, the pumping cost for the $17 \mathrm{~mm}$ diameter pipes was 2.8 (for a height difference of $3 \mathrm{~m}$ between the storage tank and the embedded pipes) to 3.4 times (for a height difference of $20 \mathrm{~m}$ ) higher compared to the $9 \mathrm{~mm}$ diameter pipe. The $17 \mathrm{~mm}$ pipe with higher flow rate would require a cooling tower with higher capacity. The cost of pipe per unit length is also higher for higher diameter pipes. Thus, the capital cost is eventually higher for higher diameter pipes.

The increase in roof and floor thickness would increase the capital cost as more concrete is used for construction. The price of concrete work varies with location. In India, concrete work costs 6000 INR per cubic meter. Thus, an increase in roof and floor thickness from 0.1 to $0.2 \mathrm{~m}$ would increase the capital cost by 1200 INR per unit floor area for single-storey buildings. The capital cost increase per unit floor area would be lower for multi-storey buildings as the 
Table 4. The inputs and outputs for the best and worst combination of the design parameters.

\begin{tabular}{|c|c|c|c|}
\hline S1. no. & Parameter & Best & Worst \\
\hline & \multicolumn{3}{|c|}{ Inputs } \\
\hline 1 & Pipe inner diameter (mm) & 17 & 9 \\
\hline 2 & Pipe thermal conductivity (W/mK) & 0.14 & 4.5 \\
\hline \multirow[t]{2}{*}{3} & Roof and floor thickness (m) & 0.2 & 0.1 \\
\hline & \multicolumn{3}{|c|}{ Outputs (diurnal average) } \\
\hline 4 & $\mathrm{OT}\left({ }^{\circ} \mathrm{C}\right)$ & 31.0 & 35.6 \\
\hline 5 & PMV (-) & 1.7 & 3.1 \\
\hline 6 & PPD $(\%)$ & 59.8 & 96.5 \\
\hline
\end{tabular}

roof of one storey would act as a floor for the next storey. In other countries, the cost of concrete work may vary considerably based on the availability of construction materials and labour costs.

At present, PEX is the most common pipe material for TABS. However, from this study, it is clear that the increase in thermal conductivity of the pipe until the thermal conductivity of the slab material would improve the cooling performance of the system considerably. Hence, various materials must be researched to identify a flexible, easy to join, leak-proof, durable and cheap pipe material that has a thermal conductivity equal to or slightly greater than that of concrete. The cost of pipe and its thermal conductivity do not have a relationship as the former depends on factors such as raw material availability and processing technique.

Thus, the best combination of these design parameters is dependent on various local factors such as the cost of building materials, labour and electricity, and the nature of building (single or multi-storey). The preferences and environmental awareness of the user also play a major role in deciding the design parameters as some users may prefer lower capital cost over lower operational cost, yet another user may be willing to invest more money to reduce energy consumption and the related environment pollution. The best combination is likely to change with time due to research innovations in pipe and building materials. Hence, the best combination should ideally be decided on a caseby-case basis. This study highlights the importance of the three design parameters as they have a significant influence on the cooling performance of TABS.

\section{Conclusions}

A room with a thermally activated building system (TABS) was simulated to quantify the influence of three design parameters on the indoor thermal comfort.

(i) Pipe diameter: Two cases, namely, constant water flow rate (Case-1) and constant inlet velocity (Case2 ), were investigated. In both the cases, an increase in pipe diameter improved the cooling performance of TABS. However, the influence of the change in pipe diameter was lower in Case-1 compared to that of Case-2.

(ii) Pipe thermal conductivity: An increase in the thermal conductivity of pipes, improved the cooling performance of TABS significantly only when the thermal conductivity of pipes was lower than that of the concrete slabs in which they were embedded.

(iii) Thickness of slabs (roof and floor): An increase in thickness of slabs decreased the fluctuation and delayed the extrema of all comfort indices. An increase in thickness of the slabs with cooling pipes embedded at a fixed depth $(0.05 \mathrm{~m})$ from the inner surface of the slabs improved the thermal comfort marginally. However, the average indoor thermal comfort deteriorated marginally if the slab thickness was increased with the cooling pipes placed at the centre of the slabs.

The combined impact of the three design parameters was also examined. The best combination of these parameters reduced the operative temperature of the indoor space by $4.7^{\circ} \mathrm{C}$ compared to the worst combination. Nevertheless, the best combination needs higher capital and operational cost, which is a function of many local factors.

\section{Acknowledgements}

This study was funded by Department of Science and Technology, Government of India (Grant No. SR/S3/ MERC/00091/2012).

\section{Appendix-A}

Material properties of air and water [28, 29]

1. The density of moist air $\left(\rho_{m a}\right)$ in $\mathrm{kg} / \mathrm{m}^{3}$ is given by,

$$
\rho_{m a}=p_{a} \times\left(1+x_{a}\right) / 461.56 /\left(0.62198+x_{a}\right) / T_{a}
$$

2. The dynamic viscosity of moist air $\left(\mu_{m a}\right)$ in $N s / m^{2}$ is given by (Tsilingiris, 2008), 


$$
\begin{aligned}
\mu_{m a}= & \mu_{a} /\left(1+\phi_{a v} \times 1.61 \times x_{a}\right) \\
& +\mu_{v} /\left(1+\phi_{v a} /\left(1.61 \times x_{a}\right)\right)
\end{aligned}
$$

where,

$$
\begin{aligned}
\phi_{a v}= & \left\{1+\left(\mu_{a} / \mu_{v}\right)^{0.5}\left(m_{v} / m_{a}\right)^{0.25}\right\} /\left\{2 \sqrt{2}\left(1+m_{a} / m_{v}\right)^{0.5}\right\} \\
\phi_{v a}= & \left\{1+\left(\mu_{v} / \mu_{a}\right)^{0.5}\left(m_{a} / m_{v}\right)^{0.25}\right\} /\left\{2 \sqrt{2}\left(1+m_{v} / m_{a}\right)^{0.5}\right\} \\
\mu_{\mathrm{a}}= & -8.3828 \mathrm{E}-7+8.3572 \mathrm{E}-8 \times \mathrm{T}_{\mathrm{a}}-7.6943 \mathrm{E}-11 \times \mathrm{T}_{\mathrm{a}}^{2} \\
& +4.6437 \mathrm{E}-14 \times \mathrm{T}_{\mathrm{a}}^{3}-1.0659 \mathrm{E}-17 \times \mathrm{T}^{4} \\
\mu_{v} & = \\
& \frac{\left(T_{a} / 647.327\right)^{0.5}}{18158+17762\left(647.27 / T_{a}\right)+10529\left(647.27 / T_{a}\right)^{2}-3674\left(647.27 / T_{a}\right)^{3}}
\end{aligned}
$$

3. The thermal conductivity of moist air $\left(k_{m a}\right)$ in $\mathrm{W} / \mathrm{mK}$ is given by,

$$
k_{m a}=\left\{k_{a}+1.61 \times x_{a}\left(0.8536 \times k_{v}-k_{a}\right)\right\} /\left(1-0.2357 \times x_{a}\right)
$$

$$
\begin{aligned}
\mathrm{k}_{\mathrm{a}}= & -0.0022758+1.1548 \mathrm{E}-4 \times \mathrm{T}_{\mathrm{a}}-7.9025 \mathrm{E}-8 \\
& \times \mathrm{T}_{\mathrm{a}}^{2}+4.1170 \mathrm{E}-11 \times \mathrm{T}_{\mathrm{a}}^{3}-7.4486 \mathrm{E}-15 \times \mathrm{T}_{\mathrm{a}}^{4} \\
k_{v}= & 3.1998 E-2 \times T_{a}-1.3309 E-4 \times T_{a}^{2}+3.8160 E \\
& -7 \times T_{a}^{3}-2 E-9 \times T_{a}^{4}
\end{aligned}
$$

4. The dynamic viscosity of water $\left(\mu_{w}\right)$ in $N s / m^{2}$ is given by,

$$
\begin{aligned}
\mu_{\mathrm{w}}= & 1.38-2.12 \mathrm{E}-2 \times \mathrm{T}_{\mathrm{w}}+1.36 \mathrm{E}-4 \times \mathrm{T}_{\mathrm{w}}^{2}-4.64 \mathrm{E} \\
& -7 \times \mathrm{T}_{\mathrm{w}}^{3}+8.90 \mathrm{E}-10 \times \mathrm{T}_{\mathrm{w}}^{4}-9.08 \mathrm{E}-13 \times \mathrm{T}_{\mathrm{w}}^{5} \\
& +3.84 \mathrm{E}-16 \times \mathrm{T}_{\mathrm{w}}^{6}
\end{aligned}
$$

5. The thermal conductivity of water $\left(k_{w}\right)$ in $\mathrm{W} / \mathrm{mK}$ is given by,

$$
\begin{aligned}
\mathrm{k}_{\mathrm{w}}= & -0.869+8.949 \mathrm{E}-3 \times \mathrm{T}_{\mathrm{w}}-1.584 \mathrm{E}-5 \times \mathrm{T}_{\mathrm{w}}^{2} \\
& +7.985 \mathrm{E}-9 \times \mathrm{T}_{\mathrm{w}}^{3}
\end{aligned}
$$

\section{List of symbols}

$\begin{array}{ll}\text { A } & \text { cross-sectional area of the pipe, } \mathrm{m}^{2} \\ \mathrm{a}_{\mathrm{k}}, \mathrm{b} & \text { constants that depend on the order of BDF } \\ \mathrm{C}_{\mathrm{p}} & \text { specific heat, } \mathrm{J} / \mathrm{kgK} \\ \mathrm{d}_{\mathrm{h}} & \text { hydraulic diameter, } \mathrm{m} \\ \mathrm{f} & \text { body force vector, } \mathrm{N} / \mathrm{m}^{3} \\ \mathrm{f}_{\mathrm{D}} & \text { Darcy friction factor } \\ \mathrm{h} & \text { step size, } \mathrm{s} \\ \mathrm{I} & \text { identity matrix, }- \\ \mathrm{k} & \text { thermal conductivity, W/mK } \\ \mathrm{m} & \text { molecular mass, } \mathrm{g} / \mathrm{mol} \\ \mathrm{n} & \text { step number }\left(\mathrm{t}_{\mathrm{n}}=\mathrm{t}_{0}+\mathrm{nh}\right),- \\ \mathrm{Pr} & \text { Prandtl number, }-\end{array}$

$\begin{array}{ll}\mathrm{p} & \text { pressure, Pa } \\ \mathrm{Q} & \text { heat source, } \mathrm{W} / \mathrm{m}^{3} \\ \mathrm{Q}_{\text {wall }} & \text { heat transfer through pipe wall, W/m } \\ \mathrm{Re} & \text { Reynolds number, }- \\ \mathrm{RH} & \text { relative humidity, } \% \\ \mathrm{~s} & \text { order of BDF, }- \\ \mathrm{T} & \text { temperature, } \mathrm{K} \\ \mathrm{t} & \text { time, } \mathrm{s} \\ \mathrm{t}_{\mathrm{a}} & \text { dry bulb temperature, }{ }^{\circ} \mathrm{C} \\ \mathrm{t}_{\mathrm{wb}} & \text { wet bulb temperature, }{ }^{\circ} \mathrm{C} \\ \mathrm{u} & \text { velocity vector, } \mathrm{m} / \mathrm{s} \\ \overline{\mathrm{u}} & \text { cross section averaged fluid velocity along the } \\ & \text { center line of a pipe, } \mathrm{m} / \mathrm{s} \\ \mathrm{x} & \text { absolute humidity, } \mathrm{kg} / \mathrm{kg} \text { of dry air } \\ \mu & \text { dynamic viscosity, } \mathrm{Ns} / \mathrm{m}^{2} \\ \rho & \text { density, } \mathrm{kg} / \mathrm{m}^{3} \\ \tau & \text { time, } \mathrm{s}\end{array}$

Subscript

$\begin{array}{ll}\text { a } & \text { air, dry air } \\ \text { ma } & \text { moist air } \\ \text { v } & \text { water } \\ & \text { vapour } \\ \text { w } & \text { water }\end{array}$

\section{References}

[1] Yeo M, Yang I H and Kim KW 2003 Historical changes and recent energy saving potential of residential heating in Korea. Energy Build. 35: 715-727

[2] Zhuang Z, Li Y, Chen B and Guo J 2009 Chinese kang as a domestic heating system in rural northern China: a review. Energy Build. 41: 111-119

[3] Bansal N K and Shail 1999 Characteristic parameters of a hypocaust construction. Build. Environ. 34: 305-318

[4] Kolarik J, Toftum J, Olesen B W and Jensen K L 2011 Simulation of energy use, human thermal comfort and office work performance in buildings with moderately drifting operative temperatures. Energy Build. 43: 2988-2997

[5] Olesen B W 2008 Using building mass to heat and cool. ASHRAE J. 54: 44-52

[6] Tian Z and Love J A 2008 A field study of occupant thermal comfort and thermal environments with radiant slab cooling. Build. Environ. 43: 1658-1670

[7] Henze G P, Felsmann C, Kalz D E and Herkel S 2008 Primary energy and comfort performance of ventilation assisted thermo-active building systems in continental climates. Energy Build. 40: 99-111

[8] Rijksen D O, Wisse C J and Van Schijndel A W M 2010 Reducing peak requirements for cooling by using thermally activated building systems. Energy Build. 42: 298-304

[9] Raimondo D, Olesen B W and Corgnati S P 2013 Field test of a thermal active building system (tabs) in an office building. In: Building Simulation (BS2013) International Conference, Chambery, France 
[10] Helsen L 2016 Geothermally activated building structures. In: Rees S (ed), Advances in Ground-Source Heat Pump Systems. New York: Elsevier Science \& Technology, pp. 423-452

[11] Leo Samuel D G, Shiva Nagendra S M and Maiya M P 2017 Feasibility analysis of passive thermally activated building system for various climatic regions in India. Energy Build. 155: 352-363

[12] Sprecher P and Tillenkamp F 2003 Energy saving systems in building technology based on concrete-core-cooling. Int. J. Ambient Energy 24: 29-34

[13] Shen C and Li X 2016 Dynamic thermal performance of pipe-embedded building envelope utilizing evaporative cooling water in the cooling season. Appl. Therm. Eng. 106: 1103-1113

[14] Jin X, Zhang X, Luo Y and Cao R 2010 Numerical simulation of radiant floor cooling system: the effects of thermal resistance of pipe and water velocity on the performance. Build. Environ. 45: 2545-2552

[15] Antonopoulos K A, Vrachopoulos M and Tzivanidis C 1997 Experimental and theoretical studies of space cooling using ceiling-embedded piping. Appl. Therm. Eng. 17: 351-367

[16] Xie J, Zhu Q and Xu X 2012 An active pipe-embedded building envelope for utilizing low-grade energy sources. $J$. Cent. South Univ. 19: 1663-1667

[17] Hauser G, Kempkes C and Olesen B W 2000 Computer simulation of hydronic heating/cooling system with embedded pipes. ASHRAE Tran. 106: 702-710

[18] Ma P, Wang L S and Guo N 2013 Modeling of TABS-based thermally manageable buildings in Simulink. Appl. Energy 104: 791-800
[19] Leo Samuel D G, Shiva Nagendra S M and Maiya MP 2017 Simulation of indoor comfort level in a building cooled by a cooling tower-concrete core cooling system under hotsemiarid climatic conditions. Indoor Built Environ. 26: 680-693

[20] Barnard C L 1996 A theory of fluid flow in compliant tubes. Biophys. J. 6: 717-724

[21] Lurie M V 2008 Modeling of Oil Product and Gas Pipeline Transportation. 1st ed. Weinheim: Wiley-VCH Verlag $\mathrm{GmbH} \& \mathrm{Co}$. KGaA

[22] Gnielinski V 1976 New equation for heat and mass transfer in turbulent pipe and channel flow. Int. Chem. Eng. 16: 359-368

[23] Weather Underground. Weather History. Available at http:// www.wunderground.com. Accessed 23 Feb 2015

[24] Stull R 2011 Wet-bulb temperature from relative humidity and air temperature. J. Appl. Meteorol. Clim. 50: 2267-2269

[25] ASHRAE 2013 ASHRAE Handbook: Fundamentals. Atlanta: ASHRAE

[26] Fanger P O 1970 Thermal Comfort Analysis and Applications in Environmental Engineering. New York: McGraw-Hill

[27] Fanger P O 1982 Thermal comfort. Malabar, FL: Robert E. Krieger

[28] The Engineering ToolBox, Moist air properties. Available at http://www.engineeringtoolbox.com. Accessed 23 Jan 2014

[29] Tsilingiris P T 2008 Thermophysical and transport properties of humid air at temperature range between 0 and $100^{\circ} \mathrm{C}$. Energy Convers. Manage. 49: 1098-1110 